On the Natural Classification of Gasteropoda.-Part I.

By Dr. J. D. MAODONALD, R.N., F.R.S.

[Read June 17, 1880.]

Is the year 1860, just twenty years ago, Professor Huxley communicated to this Society a paper of mine, on the "Classification of the Gasteropoda," founded respectively, 1st, on the sexual characters, 2nd, on the lingual dentition, and 3rd, on the auditory concretions; and, notwithstanding all that has been done of late years in this department of natural history, the General Table then given would still appear to hold its ground as a natural arrangement.

The object of this paper is to add some additional remarks and suggestions to the former one, adopting a fourth guide to the discovery of natural affinities, namely, "Representative Relationships."

The faculty of comparison should be well developed in the systematic naturalist; but we often find that it is misapplied, and superficial resemblances are assumed to be indications of genuine affinity, so that, apparently, like things are grouped together, though intrinsically bearing no natural alliance to each other. Indeed, underlying nearly all the mistakes that have been made in matters of classification, we find the occurrence of representative relationships or analogous characteristics repeating themselves in particular members of the orders, suborders, families, or even smaller groups of the Animal Kingdom. The recognition of such representative relationships, as distinguished from those of affinity, must depend upon a more general comparison of structure. Thus, breathing in air, for instance, can be easily shown to be a representative character amongst larger groups, and, of course, of great importance in neighbouring species; but it can by no means warrant the association of the members of two otherwise quite distinct groups. Yet, if we analyze the Pulmonifera of authors, what do we find? First, that all air-breatbers are placed in one category ; secondly, that they are recognized to be either operculate or inoperculate; and, thirdly, that the momentous question of being moncecious or diocious is either not noticed at all, or referred to in a casual way, the latter being indicated by the presence and the former by the absence of an operculum-though, unfortunately, some Diplommatina, which are unisexual, are inoperculate, and the anomalous bisexual genus $A m p h i b o l a$ is furnished with an operculum. 
If we now turn to the analogy of shell-characters in a general way we find :-

1st. That some Gasteropodous families are altogether naked, having no representatives furnished with a shell.

2nd. That some have both naked and shell-bearing species.

3rd. That others are all furnished with a shell, haring no naked representatives.

Under the first head would come the Nudibranchiata of authors, and the second would iuclude the Tectibranchiata, the bisexual Pulmonifera, and the Heteropoda ; while the third would comprise all the remaining families. But for the position here given to the Heteropoda, this arrangement would seem to answer very well. If, however, we take a formula derived from the above heads and apply it to the second division, some interesting results will be obtained. Referring to the Heteropoda, first, by way of illustration, we find six typical genera; two of these are entirely naked, namely Firola and Cerophora; two others have a shell of only sufficient size to protect the viscera, viz. Cardiapoda and Carinaria; while the two remaining genera have an operculate shell, completely including the retracted animal, Oxygyrus and Atlanta. On attempting to arrange the shells we see that those of Cardiapoda and Oxygyrus are cartilaginous with an involute nucleus, while those of Carinaria and Atlanta are bard and vitreous-looking with a spiral nucleus. Two distinct groups are thus clearly indicated.

First Group.

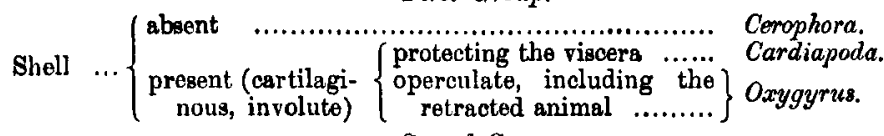

Second Group.

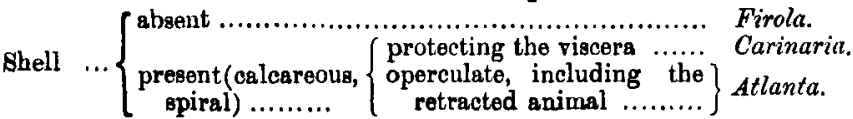

It might be asked, why Firola should be placed with Carinaria and Cerophora with Cardiapoda. But the only reason that need be given is, that the general appearance of the animals and the comparison of their lingual dentition would appear to indicate the position assigned to them.

Many persons think that the Heteropoda should be separated from the Gasteropoda as a distinct class, but this would scarcely appear to be necessary. There is a much wider difference between 
a Bulla and a Strombus than between the latter and an Atlanta, for example; and in reference to the genus Phorus, I find the following remarks in my note-book:- "The animal of Phorus is strikingly suggestive of Atlanta or Oxygyrus, and it has been remarked that the dentition closely resembles that of the Heteropod (Mörch). I am strongly inclined to think that the Phoride will be found to form the connecting link between the Gasteropoda proper and the Heteropods." To return to the subject from this digression, it will be easy to see that Firola and Cerophora are representatives in the two groups above given-that Carinaria represents Cardiapoda, and Atlanta Oxygyrus. Now if we deal with the monocious Gasteropoda as a whole, we shall have the results as given in the following Table :-

\section{Class Gasteropoda.}

Division I. MONGECIA (sexes combined).

Subdivision I. Lingual dentition typically pavemental *.

Order I. PNeимокорнола (lung-bearing, or respiring in air).

Suborder 1. Pulmonata (with air-chamber only).

A. Habit terrestrial.

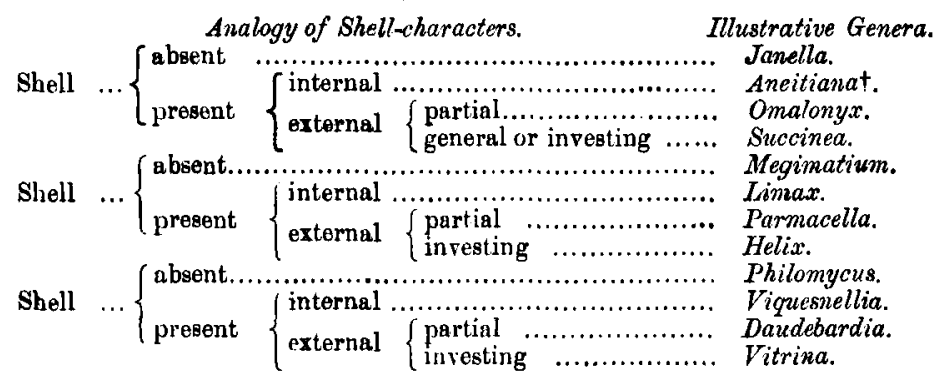

Suborder 2. Pulmobranchiata (having both an air-chamber and a ciliated surface or branchia for respiration in water).

B. Habit aquatic.

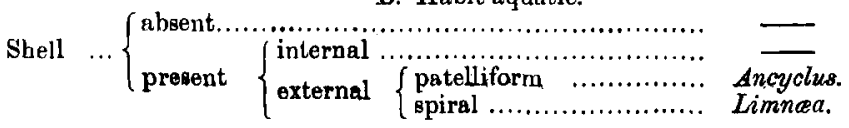

* In some instances apparently strap-like, by reduction of the members of the pleure.

† A bitentaculate olug, occurring in N.S. Wales and the New Hebrides, desoribed by me in Ann. \& Mag. Nat. Hist. 1856, ser. 2, vol. sviii. p. 33. 
C. Habit. Estuary and marine.

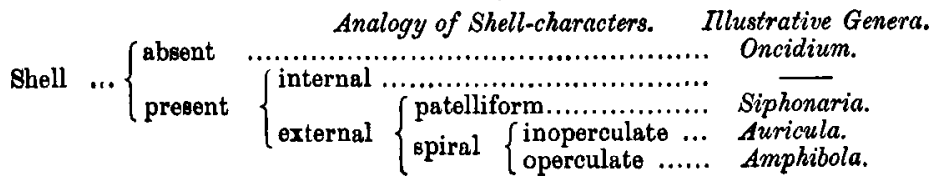

Order II. APNevmonopura (having no air-chamber).

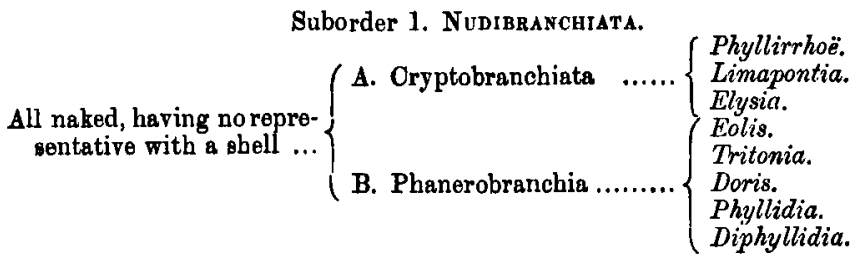

Suborder 2. Tectibranchiata.

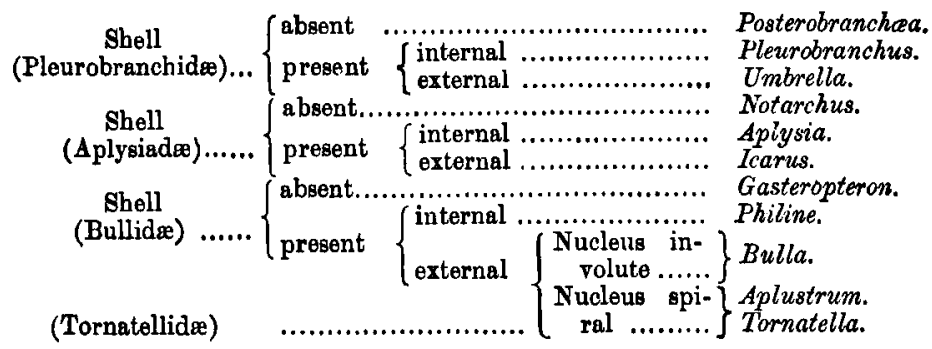

Subdivision II. Lingual membrane strap- or ribbon-like *.

Order I. Heterogzossa. Teeth in five to eight longitudinal series, variable in form, the larger ones with opaque tips. Foot without any lateral fringe. Shell symmetrical._Gray.

Suborder 1. Polyplacophora. Shells forming a linear imbricate series on the middle of the back.

Ex. Chiton, Chitonellus, \&rc.

Suborder 2. Oyclobranchia. Gill lamellar, forming a more or less complete ring beneath the mantle.

Ex. Patella, Patina.

Suborder 3. Cerryicobranchia. Gill single, to the left on the back of the neck.

Ex. Tectura, Gadina, Lepita.

* Dentition typically multiserial, with rhachis and pleure distinctly differentiated, the dental processes being recurred from the fore part of the basal plates (anaclodontous). 
Suborder 4. Orarobranchia. Gills two, symmetrical, tufted on the back of the neck.

Ex. Dentalium, Entalis.

Order II. Raphidoglossa. Teeth in numerous longitudinal series, the central 5.1 .5 , variable in form ; Iateral very numerous, more slender, curved at the tip. -Gray.

Suborder 5. Dicranobranchila. Gille two, symmetrical on the back of the neck.

Ex. Deridobranchus (a naked form), Scutus, Emarginula, Puncturella, Fissurella.

Suborder 6. Schismatobranchia. Gills in two plumes on the left side of the gill-cavity; body and shell spiral.

Ex. Teinotis, Padollus, Haliotus, Scissurella.

Suborder 7. Scotibranchia. Gills in a spiral line on the left side; body, shell, and operculum spiral.

Ex. Stomatella, Trochus, Turbo, Rotella, Nerita, Neritina, and Navicella.

Suborder 8. Pseudobranchra. Having no distinct gill, being in reality pulmonate.

Ex. Helicina, Proserpina, Ceres.

As to the propriety of the application of the term Pulmonata to the terrestrial monœcious Gasteropoda there need be no question; but to justify the use of the second subordinal term Pulmobranchiata the following reasons may be adduced.

1st. Siebold mentions that the raised vascular network of the lining of the pulmonary cavity is coated with cilia in the aquatic species, and he further says that he found ciliated epithelium in the pulmonary cavity of the Limnaida, though not in that of Limax or Arion. Ancylus was formerly placed in the Inferobranchia, though really having no alliance with them; and a simple, probably ciliated enlargement on the left side, concealed under a fold of the mantle, has been accepted and figured as a true brauchia by both Treviranus and Vogt. S. Clessin thinks that the Limnaidae normally respire water, though it should be remembered that water only finds access to the lung-chamber when the animals are very young, though the recorder of this fact (A. Pauly) is of opinion that this may be permanently the case with those species which habitually live in deep water.

2nd. In the amphibious genus Oncidium, Ehrenberg noticed the occurrence of more than twenty small ramified organs at the posterior part of the back, which he regarded as true branchio; 
and I find that Jhering has observed the same structures in the genus Peronia, which lives between tide-marks, thus confirming Ehrenberg's view.

8rd. I can vouch myself for the coexistence of true branchim within the pulmonary chamber in both Siphonaria and Amphibola, having made drawings of them from the recent animals.

The branchial characters of the Nudibranchs have been so worked upon and variously represented by different writers, that I have only for the present made two sections of them. The first, or the Cryptobranchia, to include those forms which at best only present a ciliated surface for respiration ; and the second, or Phanerobranchia, those in which the branchial organs are plainly discernible. Perhaps a much more satisfactory guide to classification will be found in the lingual and labial dentition, which, though exceedingly perplexing to the student, will, I am quite sure, be better understood when opportunities are more favourable for direct comparison and legitimate deduction.

There are, indeed, certain principles to be borne in mind when we enter upon the study of the dentition of a family or larger group exhibiting great diversity as to the number of the elementary parts and their particular form. The essential points to know are the following :-

The typical lingual dentition presents a central region, or rhachis, and two lateral parts, or pleura so-called. The dental organs are disposed in transverse rows succeeding one another from bifore backwards; and the lingual membrane upon which they are arranged is quite homogeneous and more or less corneous in consistency, supported by the lingual cartilages, and forming the floor and sides of the lingual sac, which latter usually projects downwards and backwards below the œsophagus from the floor of the mouth.

When the lingual membrane is comparatively short and broad and the teeth numerous and similar, the dentition sssumes the form of a pavement; but, on the contrary, if the membrane is very much longer than it is broad, and there is a marked distinction between the rhachis and pleurm, it acquires the character of a "ribbon" or "strap."

It is curious to remark, and it bears largely on the soundness of the primary division in the foregoing table of classification, that the dentition is typically pavemental in the Moncecious and ribbon-like in the Diacious Gasteropoda; and, with certain exceptions, even admitting of explanation, the auditory sacs contain 
otoconia in the former case and single spherical otoliths in the latter. The dental organs themselves usually consist of a basal plate of attachment, with which the dental tubercles or fangs, which always point backwards, are connected. They are subject to depreciation or suppression, and further development or increase, both wholly or as to their component parts, which has, no doubt, given rise to all the diversity of character which we observe in the different families of Gasteropoda. Thus we often find the dental processes so large as to quite absorb the basal plates, while in other cases the basal plate alone remains, as it were preparatory to its complete extinction. It will be seen therefore that if the pleura on each side gradually undergoes suppression, a typical pavement will be made to assume a more or less strap-like appearance; and this character will be made more deceptive by the coincident development of the rhachis*. On the other hand, if the rhachidian series is suppressed, the dentition will, of course, be divided into two lateral portions and thus become more or less decidedly double, the effect being enlanced by the greater development of the central part of each pleura. IJlustrations of these conditions are to be found in all the principal sections of the Gasteropoda. I have only to regret at present that my time will not permit me to make this subject clearer by special reference to examples; but I hope to do so at some future period as an introduction to the second part of this paper, taking up the classification of the Gasteropoda Diœcia.

Observations on Ants, Bees, and Wasps; with a Description of a new Species of Honey-Ant.-Part VII. Ants. By Sir JoHN Luввоск, Bart., M.P., F.R.S., F.I.S., D.C.L., LL.D., ViceChancellor of the University of London.

[Read June 17, 1880.]

(Plate VIII.)

Power of Communication by something approaching to Language. Is my previous papers many experiments have been recorded, in which I have endeavoured to throw some light on the power of

* For example, in the Eolide and neighbouring genera, the affinity of which cannot be doubted, the gradual reduction from a typical paremental dentition to the pseudo strap-like form may be easily observed. 